\title{
Student Engagement through Visual Thinking Routines
}

\author{
By Alain Gholam*
}

\begin{abstract}
Visual thinking routines are principles based on several Western theories, approaches, and strategies. Such routines, which are usually used again and again in the classroom, promote thinking skills, call for collaboration and sharing of ideas, make thinking and learning visible, and above all, promote student engagement. Visual thinking routines were implemented in the graduate course, "EDEL606, Elementary Science and Mathematics Methods" at the American University in Dubai. The aim of this qualitative study was to examine student teachers' attitudes towards visual thinking routines. The use of such visual thinking routines in the teaching methodology course helped student teachers acquire hands-on experience on the usage of visual thinking routines, and hence, transformed the learning acquired to their classroom. At the end of the course, 5 students, enrolled in EDEL606, answered a simple question: "What did you like most about visual thinking routines?" The results showed that student teachers relished and appreciated the use of visual thinking routines in the course and the manner in which such routines allowed for organization, variety, thinking, and student engagement. As with all original, new, and unique resources, visual thinking routines are not free of challenges. To make the most of this useful and valued resource, educators, need to comprehend, model and spread an awareness of the effective ways of using such routines in the classroom. It is crucial that such routines are meaningfully and effectively integrated into the curriculum in order to reinforce student engagement and make sure students are actively involved in the learning process.
\end{abstract}

Keywords: student engagement, thinking skills, visual thinking routines, 21 st century education.

\section{Introduction}

Let us take a minute to reflect on the concept of "human history". What happened in the past? What is happening at the moment? What is going to happen in the future? Well, we can all agree, to a certain extent, that at different and distinctive periods of human history, individuals have encountered exclusive sets of challenges, trials, tests, and dilemmas that have forced them to change the way they think and the way they interact with one another and the world around them. We, teachers and educators, are among these individuals. Not only us, teachers and educators, but also our students are among these individuals. We need to pause for a while and think about our students. What is it that we exactly want from them? Do we want them to gain knowledge? Or do we want them to be well equipped with factual information? Or do we want them to read, write, add, and subtract? Or do we want them to have a repertoire of

*Assistant Professor, American University in Dubai, UAE. 
important skills that will prepare and help them encounter the challenges of the present and future? In order for our students to face all the obstacles of today and tomorrow, we, teachers and educators, need to be able to equip them with the necessary tools that are at our own disposal. Hence, we need to make sure our lessons are highly engaging, motivating, and creative. We need to make sure our classrooms embrace a culture that includes the following chief factors: observing, asking questions and wondering, experimenting, thinking, constructing, communicating, reflecting, and connecting to real life. In summary, we need to make sure our students are actively engaged in the learning journey and are constructing their own knowledge.

One of the most essential components of $21^{\text {st }}$ Century Education is student engagement. Marzano et al. (2013) argued that engagement is not an easily defined construct. According to the National Survey of Student Engagement (NSSE, n.d.), student engagement represents two critical features of collegiate quality: The first is the amount of time and effort students put into their studies and other educationally purposeful activities, and the second is how the institution deploys its resources and organizes the curriculum and other learning opportunities to get students to participate in activities that decades of research studies show are linked to student learning. Visual thinking routines are examples of tools used by teachers to engage students in the learning process. Ritchhart (2015) explained that since the publication of "Making Thinking Visible" (Ritchhart, Church, \& Morrison, 2011), teachers around the world have been introduced to thinking routines. "Teachers tend to find that these routines play well in their classroom and that they provide for active, engaged learning while helping reveal students' thinking" (Ritchhart, 2015, p. 177). Ritchhart and Perkins (2008) provided a list of characteristics that anchor visible thinking. Some of these characteristics include: learning is a consequence of thinking, the development of thinking is a social endeavor, and fostering thinking requires making thinking visible. Therefore, one can't deny the fact that visual thinking routines call out for student engagement and reinforce thinking skills and a variety of other $21^{\text {st }}$ century skills. Ritchhart (2015) strongly believed that such routines should be part of a school's culture due to the following reasons: 1). help direct teachers' attention straight to the issue of thinking, 2). provide specific practices that teachers can employ and see results almost immediately, 3). make students' thinking visible and thus provide teachers with an example of the good thinking their students are capable of doing, 4). encourage action and discussion around thinking, 5). help build the infrastructure for thinking and learning in the classroom, 6). connect easily to the other cultural forces, as teachers work with routines, they often notice changes in their language, in the creation of opportunities, in their interactions, and so on. Ritchhart, Turner, and Hadar (2009) examined the benefits of visible thinking and explored a method for uncovering students' thinking about thinking. The method was studied within the context of an ongoing, multi-year intervention designed to promote the development of students' thinking dispositions. They developed a concept-map instrument that classroom teachers could implement, and an analytic framework for interpreting the students' responses was presented. After analyzing 239 concept maps from 
grades 3 through 11, Ritchhart et al. (2009) suggested that students' conceptions of thinking did improve with age and could be developed through a classroom culture where thinking was modeled and rich opportunities for thinking were present. In the "Visible Thinking Project", Ritchhart, Palmer, Church, and Tishman (2006) reported several conclusions related to the effectiveness of visible thinking. They realized that both students and teachers come to view and approach thinking and learning differently as a result of using routines. They also learned that students become more autonomouslearners and teachers come to see students as more thoughtful and engaged. Finally, Ritchhart et al. (2006) concluded that learning becomes a collective endeavor involving both teachers and students.

A teacher is held accountable of preparing students to contribute and subsidize to the future world. Learners need to be equipped with skills needed to face problems and create new products and services. Learning for work and life in our times means helping as many children as possible to learn to apply $21^{\text {st }}$ century skills and reach a solid understanding of different core subjects (Trilling \& Fadel, 2009). Implementing visual thinking routines in the classroom will aid teachers and educators in making sure that $21^{\text {st }}$ century education reaches every child. When used in Pre $\mathrm{K}-12$ settings, such tools will allow for student engagement, thinking, curiosity, and creativity.

\section{Thinking Skills: Identified and Explained}

Think! Think! Think! We hear teachers asking their students to keep on thinking. Thinking is a major component in schools, as students are encouraged to think at all times and everywhere. Students are asked to think in class, in the playground, on the bus, in the hallway, and at home. Hence, student thinking is always occurring and happening. But let us stop for a while and think about the various definitions of thinking. What is meant by the term, "thinking"? What makes thinking such a special tool? What are thinking skills? How does a teacher know that a child is thinking? According to the Oxford dictionary, thinking is the process of considering or reasoning about something and represents a person's ideas or opinions. Ruggiero (2014) stated that thinking is a focused mental activity over which we exercise some control and helps us resolve a problem, make a decision, or achieve a wish to understand. It is a process involving mental operations such as induction, deduction, classification, and reasoning explained Arends (2014). So far, the various definitions suggest that thinking is purposeful and involves a certain cognitive process. In conclusion:

"Thus, thinking skills are the mental processes we use to do things like solve problems, make decisions, ask questions, make plans, pass judgments, organize information, and create new ideas. Often we're not aware of our thinking - it just happens automatically." (Moore, 2015, p. 376)

Now that we are familiar with the various definitions of thinking, we need 
to consider some essential questions: What types of thinking do teachers want to reinforce in their classroom? Do they want their students to deduce, analyze, interpret, reason, classify? What types of thinking does this particular Science lesson call for? What about this particular Social Studies lesson? What thinking does it reinforce? Ritchhart, Church, and Morrison (2011) clarified:

"We need to be aware of the kinds of thinking that are important for scientists (making and testing hypotheses, observing closely, building explanation....), mathematicians (looking for patterns, making conjectures, forming generalizations, constructing arguments....), readers (making interpretations, connections, predictions....), historians (considering different perspectives, reasoning with evidence, building expectations....), and so on, and make these kinds of thinking the center of the opportunities we create for students." (pp. 10-11)

The types of thinking that are essential and central to different subject areas were mentioned above. "But are there particular kinds of thinking that serve understanding across all disciplines? Types of thinking that are particularly useful when we are trying to understand new concepts, ideas, or events?" (Ritchhart, Church, and Morrison, 2011, p. 11). Ron Ritchhart and colleagues David Perkins, Shari Tishman, and Patricia Plamer came up with eight thinking moves that are integral to understanding and without which it would be really hard to say we had gained understanding (Ritchhart, Chruch, \& Morrison, 2011): 1) observing closely and describing what's there, 2) building explanations and interpretations, 3) reasoning with evidence, 4) making connections, 5) considering different viewpoints and perspectives, 6) capturing the heart and forming conclusions, 7) wondering and asking questions, and 8). uncovering complexity and going below the surface of things. While these eight thinking moves are essential and show understanding, they are by no means exhaustive (Ritchhart et al., 2011, p. 13): "We offer up this list as a useful starting place, and no more." Some additional types of thinking that seem useful in the areas of problem solving, decision making, and forming judgments included: 1) identifying patterns and making generalizations, 2) generating possibilities and alternatives, 3) evaluating evidence, arguments, and actions, 4) formulating plans and monitoring actions, 5) identifying claims, assumptions, and bias, and 6) clarifying priorities, conditions, and what is known (Ritchhart et al., 2011).

\section{Visual Thinking Routines: What? Why? How?}

We can agree that thinking is an integral part of learning. However, we must not forget that thinking is invisible. So, what is really meant by the term, visible thinking? To start with, visible thinking refers to any kind of observable representation that documents and supports the development of an individual's or group's thoughts, questions, reasons, and reflections: mind maps, charts and lists, diagrams, worksheets are considered visible thinking if and only if they 
reveal the students' unfolding ideas as they think and reflect about a certain issue or topic (Tishman \& Palmer, 2005). Hattie (2012) differentiated between two visible aspects of thinking: one aspect refers to making student learning visible to teachers, and hence, ensuring clear identification of the attributes that made a visible difference to student learning, while a second aspect refers to making teaching visible to the student, so that they learn to become their own teachers, which is the core attribute of life-long learning or self-regulation.

Now, that we are more familiar with the term, "visual thinking" let us consider another vital question: What tools are used to make thinking visible? Tishman (2002) provided an example by stating that questions, such as, "What is going on here?" "What do you see that makes you say so?" do call for visible thinking. Ritchhard et al. (2011) described, "Open ended questions - as opposed to closed- ended, single-answer questions - are generally advocated as means of pushing beyond knowledge and skill and toward understanding" ( $p$. 30). Listening is another tool that is used to make thinking visible. Listening conveys a sense of respect for and an interest in the learner's contributions, and when this is present, students are more willing to share their thinking and put forth their ideas (Ritchhard et al., 2011). Other tools that can be used to make student thinking visible are visual thinking routines, which are often used as documentation (Ritchhard et al., 2011). Such tools are referred to as routines because they represent a sequence of actions designed to achieve a specific outcome in an efficient manner (Ritchhart, 2015). Visual thinking routines were first designed by the Faculty at the Harvard Graduate School of Education:

"Thinking routines are one element of an initiative called Visible Thinking that we, our colleagues at Project Zero, and collaborators in various schools have developed. In our research, we have explored the practicality of using thinking routines and documentation as classroom learning tools, developed a framework for pursuing cultural transformation in classroom and schools, and devised tools for integrating the arts. This work has spanned elementary through university settings, included both public and independent schools, and involved schools from the United States, the Netherlands, Sweden, Belgium, and Australia" (Ritchhart \& Perkins, 2008, p. 57)

So, why visible thinking routines in the classroom? The research investigated by the Harvard Project yielded a number of reasons that supported the benefits of implementing visible thinking routines in the classroom (Visible Thinking, n.d.). First, humans learn best what they can see and hear. Second, visible thinking includes a variety of ways of making students' thinking visible to themselves, to their classmates, and to their teacher. Hence, students find themselves more engaged in such routines and come to manage it better for learning and other purposes. Third, when students participate in visual thinking routines, they engage in metacognition - they think about their thinking. "When we think about our thinking, we are not only reviewing what we have done or the products of thinking we generated but also examining the processes we used or didn't use" (Ritchhart, 2015, p. 69). Fourth, it becomes evident that 
school is about exploring new ideas rather than memorizing. Fifth, visual thinking routines are considered helpful tools for teachers, as they can see students' thinking, misconceptions, prior knowledge, reasoning, and understanding. Teachers can then address these difficulties and push their students' thinking further by starting from where they are.

In the classroom, visual thinking routines are used as tools, structures, and patterns of behavior (Ritchhart et al., 2011). As tools, Ritchhart et al. (2011) asserted that they are used over and over again in the classroom to support specific thinking moves such as: making connections, describing what is present, building explanations, considering different viewpoints and perspectives, capturing the heart and forming conclusions, and reasoning with evidence. Ritchhart et al. (2011) carried on to explain that visual thinking routines are also used as structures, where they follow a natural progression in which each step builds on and extends the thinking of the previous one: "Therefore, in using the routines the goal is never simply to fill out or complete one step and move on to the next but to use the thinking occurring at each step in the subsequent steps" (p. 47). Finally, visual thinking routines are used in the classroom as patterns of behavior: they are used regularly and become part of the pattern of the classroom, and students internalize messages about what learning is and how it happens (Ritchhart et al., 2011). Visual thinking routines are designed in such a manner to serve different purposes in the classroom: routines for introducing and exploring ideas (Examples: See-Think-Wonder, Zoom In, Think-PuzzleExplore, 3-2-1 Bridge, Compass Points), routines for synthesizing and organizing ideas (Examples: Headlines, Color-Symbol-Image, Generate-Sort-ConnectElaborate, The 4C's), and routines for digging deeper into ideas (Examples: What Makes You Say that?, Circle of Viewpoints, Step Inside, Claim-SupportQuestion) (Ritchhart et al., 2011).

\section{Method}

The research was carried out as a part of EDEL606: Elementary Science and Mathematics Methods, a Graduate Education course at the American University in Dubai. The course focused on implementing visual thinking routines to ensure a student centered learning atmosphere. In every session, student teachers enrolled in this course were asked to make their thinking visible using a number of visual thinking routines.

\section{Participants}

The research was carried out in fall 2015 and consisted of 5 student teachers (1 male and 4 females) enrolled in EDEL606. The participants were Science and Math Elementary and Preschool teachers and came from different nationalities. One teacher was Egyptian, two were Lebanese, one was Canadian, and one was Irish. One teacher student was teaching at the preschool level, four at the elementary level, and one was not teaching at the time. The teaching 
experience of the participants ranged from 0 years (1 participant), 4 to 8 years (2 participants), and 10 to 17 years (2 participants).

\section{Data Collection}

The main purpose of the research was to identify student teachers' perception on visual thinking routines. In order to do so, the student teachers were asked to complete a reflection paper at the end of the course and answer one question that asked what they liked most about the visual thinking routines implemented in the Elementary Science and Mathematics Method course. Participants were afforded the chance to express themselves while leaving space for freedom and spontaneity.

\section{Data Analysis and Discussion}

The responses were then analyzed in order to reach meaningful themes related to the student teachers' perceptions of visual thinking routines. Student teachers' reflections were read multiple times while briefly making notes and highlighting relevant or interesting information. Further analysis attempted to categorize the information into minor and major categories. The results show that student teachers enjoyed the way visual thinking routines were implemented in the course. Four themes emerged and showed the manner in which such routines allowed for organization and structure, variety, thinking, and student engagement.

The first identified theme was that visual thinking routines opened the space for organization and structure. All participants included elements of organization and structure in their responses. Some student teachers agreed that visual thinking routines were easy to administer and didn't take away from class time. Other student teachers discussed that visual thinking routines could be implemented any time during the class session. They reported, "...it was used at the beginning of the class, during the class, or even at the very end." They also believed that such routines were hands-on, useful, simple, and easy to use. They reported, "....wasn't simply an extra task or burden ... extremely practical and easy to use." Student teachers mentioned the fact that they enjoyed visual thinking routines because after a few sessions such engagements became routines and they knew what was expected from them. They reported, ".....became a routine and knew what we had to do next...we were familiar with the steps." Some student teachers discussed that visual thinking routines are designed in such a way to include steps that build on the previous ones. They reported, "... a meaningful flow was evident....starts with simple questions and continues with more challenging ones."

The second identified theme was that visual thinking routines allowed for variety. Student teachers found that visual thinking routines were efficient because they could be used for several purposes. Visual thinking routines could be used to start discussions or debates. They could be used to observe, think, 
reflect, and wonder about certain things or topics. They could even be used for assessment purposes. Student teachers responses included the following: "...the discussions brought in were extremely meaningful and interesting", "....we used them to observe different images, to think about different images, and to ask relevant meaningful questions", "....we would discuss and reflect on our responses and engage in debates", and "...could be used as a pre-assessment, formative assessment, and summative assessment." Some student teachers explained that visual thinking routines could be used with a number of resources: "....could be used after reading a case study or observing an image," and "...could be used after watching a short video or reading a story." Other student teachers explained that they enjoyed the implementation of visual thinking routines because they were able to express their thoughts and ideas in various ways, as different routines involved different tasks. Student teachers reported: "....at times we would be asked to draw or write," and "....we could write words or sentences."

The third identified theme was that visual thinking routines reinforced thinking skills. Student teachers considered that good thinking involved abilities, attitudes, and alertness. According to a student teacher: "....technically this is called a dispositional view of thinking." Other student teachers mentioned that critical thinking is not a skill that could be developed over night, and rather relied on learning experiences that could enrich the art form of thinking: ".... with visual thinking routines we were able to go beyond the superficial and delve deeper to a complex idea." They strongly believed that visual thinking routines moved away from the basics of facts on to deeper meaning of concepts. Some student teachers reported the following: "...... When one thinks about math and science, he/she thinks of math formulas, labs, and scientific methods. However, to tie in visible thinking routines in math and science, you are able to see thinking being displayed visibly which definitely promotes higher order thinking." As learners, through the use of visual thinking routines, student teachers were able to utilize a number of $21^{\text {st }}$ century skills as HOTS - higher order thinking skills. One reported: "I analyzed, evaluated, and interpreted." Another reported the following: "I synthesized, reflected, and extended my thinking." Student teachers also believed that visual thinking skills opened the door for communication and collaboration skills, as often, they were asked to think and reflect collaboratively. A student teacher reported: "...I collaborated, contributed, and communicated with my classmates on various topics." Another student teacher reported: "...It was amazing how we were sometimes thinking altogether, reaching different conclusions, and reflecting with one another."

The fourth identified theme was that visual thinking routines strengthened student engagement. Student teachers agreed that students were actively involved in their learning process. They were asking questions, thinking, reflecting, analyzing, interpreting, discussing, sharing, and learning together. Student teacher reported: "...We were at the center of the learning," "...Rather than listening to a lecture, we were involved in every session," ".....The sessions were very hands-on as we were always thinking together and reflecting on our thoughts," 
"...Sharing time was amazing as we could all learn from one another," "...Every single session of the course included hands-on activities that began by exploring what we already knew about the subject," and "We quickly came to realize that this was not the traditional classroom where the teacher will bestow us with the knowledge but rather, we will construct that knowledge together." A student teacher reported the crucial role visual thinking routines played by involving each and every student, even the shy or quiet ones: "....By allowing students to visually think in isolation and then share their thinking, or visually think with their classmates, visual think routines offer new heights in student engagement." Another student teacher explained that language used in the visual thinking routines encouraged student engagement as they sent the message that there is was no right or wrong answer: "........so all students will be motivated to express their thoughts and ideas.... I believe that creating such a welcoming learning environment where everyone's opinion is respected is needed in our schools to encourage students to think and express their thoughts." Student teachers enjoyed the visual thinking routines because they were able to connect them to any content or any student-centered model they learned in the course, such as: Inquiry Based Learning, Problem Based Learning, and Discovery Learning. They explained that Inquiry Based Learning focused on questioning, critical thinking, and problem solving, whereas Problem Based Learning focused on solving a problem and acquiring knowledge, visual thinking routines could be utilized to facilitate the end process for all. In addition, visual thinking routines could also be part of Discovery Learning. Student teachers reported the following: "...Visual thinking routines will be an integral part of my math and science lessons especially as I am able to connect it to any content and model we learned or discussed in this course such as: Inquiry Based Learning, Problem Based Learning, or Discovery Learning," "...With visual thinking routines, we were always tuning in, finding out information, going further and making connections... this is all part of Inquiry Based Learning," "....By allowing students to visually think through a compilation of routines, students can be guided or led to freely discover as they please," "....through visual thinking routines our thinking was always pushed further to reach a conclusion or solve a certain problem," and "....Visual thinking routines are great tools to be implemented in inquiry based classrooms as they involve students in questioning and reaching conclusions."

It is significant that student teachers enrolled in EDEL606 perceived visual thinking routines as tools used in the classroom to promote student engagement, thinking, and $21^{\text {st }}$ century skills. Their findings coincide with previous research which stated that visual thinking routines were implemented in the classroom to build and construct a deeper understanding of content, develop a greater awareness of thinking processes, enhance students' engagement and independence, and guide independent learners capable of directing and managing their own cognitive actions (Ritchhart, Chruch, \& Morrison, 2011). It was also evident in the student teachers' responses that visual thinking routines include questions that require more than simply saying yes or no. Such findings coincide with Salmon (2010) who explained that visual thinking routines include questions that 
trigger different levels of thinking and they can be used as tools to help students connect to their previous knowledge and dig deeper in the content.

\section{Conclusions}

Given the benefits and importance of including visual thinking routines in daily curricula, how do schools create a thinking culture? What are the essential elements needed to make sure visual thinking routines are effectively and efficiently implemented in schools? First, schools need to believe in a culture of thinking. Therefore, it is important that school administrators and coordinators design curricula that promote student engagement, thinking, questioning, and $21^{\text {st }}$ century Education. Second, teachers should be well equipped with the knowledge and skills needed to design and implement effective visual thinking routines in the classroom. In order to do so, teachers need to participate in study group programs related to visual thinking routines. Teachers need to have quality time to share and exchange ideas acquired from the study group programs. Third, teachers should be given a trial period to implement visual thinking routines in the classroom and prepare an evaluation of the process: the strengths, the weaknesses, what could be done better, etc. Fourth, trained teachers should offer hands-on training to the ones who are still new and are not familiar with the use of visual thinking routines. Fifth, teachers should participate in ongoing professional development programs related to visual thinking routines. Such ongoing professional development programs help teachers stay up to date with the recent trends in visual thinking routines.

Teachers prepare students for the future. Whether we like it or not, we can't teach our students the way we taught fifteen years ago. We, educators, need to make sure we equip our students with the skills and knowledge they need to successfully face the outcomes of the $21^{\text {st }}$ Century. We need to make sure we prepare them for the future and embark them on a leading career path. To do so, students need to be active participants in the learning process. Students, collaboratively, need to observe their surroundings, ask questions and wonder, experiment, predict, formulate hypothesis, test hypotheses, arrive to conclusions, communicate their findings, and definitely take action to serve the world. Hence, visual thinking routines in the classroom will can contribute to the $21^{\text {st }}$ century education.

\section{References}

Arends, R. (2014). Learning to teach. McGraw-Hill Higher Education.

Soundout. (2015). Defining student engagement: a literature review. Retrieved from http://bit.ly/2r4UgKx.

Hattie, J. (2012). Visible learning for teachers: Maximizing impact on learning. Routledge.

Marzano, R. J., \& Pickering, D. J. (2013). The highly engaged classroom. Solution Tree Press. 
Moore, K. D. (2015). Effective instructional strategies: From theory to practice. Thousand Oaks: Sage Publications.

NSSE - National Survey of Student Engagement. (n.d.). About NSSE. Retrieved from http://bit.ly/2rXKUhO.

Ritchhart, R. (2015). Creating cultures of thinking: the 8 forces we must master to truly transform our schools. John Wiley \& Sons.

Ritchhart, R., Church, M., \& Morrison, K. (2011). Making thinking visible: How to promote engagement, understanding, and independence for all learners. John Wiley $\&$ Sons.

Ritchhart, R., Turner, T., \& Hadar, L. (2009). Uncovering students' thinking about thinking using concept maps. Metacognition and Learning, 4(2), 145-159.

Ritchhart, R., \& Perkins, D. (2008). Making thinking visible. Educational Leadership, 65(5), 57-61.

Ritchhart, R., Plamer, P., Chruch, M., \& Tishman, S. (2006). Thinking routines: Establishing patterns of thinking in the classroom. Paper presented at the annual meeting of the American Educational Research Association, San Francisco.

Ruggiero, V. R. (2014). The art of thinking: A guide to critical and creative thought. Pearson Higher Ed.

Salmon, A. K. (2010). Tools to enhance young children's thinking. YC Young Children, (5), 26.

Tishman, S., \& Palmer, P. (2005). Visible thinking. Leadership Compass, 2(4), 1-3.

Tishman, S. (2002). Artful reasoning. In T. Grotzer, L. Howick, S. Tishman, \& D. Wise (Eds.), Art works for schools: A curriculum for teaching thinking in and through the arts. Lincoln, MA: DeCordova Museum and Sculpture Park.

Trilling, B., \& Fadel, C. (2009). 21 st century skills: Learning for life in our times. San Francisco, CA: Jossey-Bass.

Visible Thinking. (n.d.). Visible thinking in action. Retrieved from http://bit.ly/1IqgnZw. 
